\title{
Intensity and memory characteristics of near-death experiences
}

\author{
Charlotte Martial $^{\mathrm{a}, *}$, Vanessa Charland-Verville ${ }^{\mathrm{a}}$, Héléna Cassol ${ }^{\mathrm{a}}$, Vincent Didone ${ }^{\mathrm{b}}$, \\ Martial Van Der Linden ${ }^{\mathrm{c}}$, Steven Laureys ${ }^{\mathrm{a}, *}$

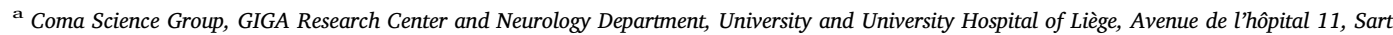 \\ Tilman, 4000 Liège, Belgium \\ b Psychology Research Unit, Cognition and Behavioral, University of Liège, Place des Orateurs 2, 4000, Sart Tilman, 4000 Liège, Belgium \\ c Cognitive Psychopathology and Neuropsychology Unit, University of Geneva, Boulevard du Pont d'Arve, 40, CH-1205 Geneva, Switzerland
}

\section{A R T I C L E I N F O}

\section{Keywords:}

Near-death experience

Memory

Intensity

Phenomenological characteristics

Greyson NDE scale

Memory Characteristics Questionnaire

\begin{abstract}
A B S T R A C T
Memories of Near-Death Experiences (NDEs) seem to be very detailed and stable over time. At present, there is still no satisfactory explanation for the NDEs' rich phenomenology. Here we compared phenomenological characteristics of NDE memories with the reported experience's intensity. We included 152 individuals with a self-reported "classical" NDE (i.e. occurring in lifethreatening conditions). All participants completed a mailed questionnaire that included a measure of phenomenological characteristics of memories (the Memory Characteristics Questionnaire; MCQ) and a measure of NDE's intensity (the Greyson NDE scale). Greyson NDE scale total score was positively correlated with MCQ total score, suggesting that participants who described more intense NDEs also reported more phenomenological memory characteristics of NDE. Using MCQ items, our study also showed that NDE's intensity is associated in particular with sensory details, personal importance and reactivation frequency variables.
\end{abstract}

\section{Introduction}

Since the expression "Near-Death Experience" (NDE) was first used in literature to describe memory of impending death situations (Heim, 1891), further work has been devoted to this type of experience in an attempt to understand its singularity. Nonetheless, very few scientific articles have examined the particularity of NDE memories (see Greyson, 2007; Palmieri et al., 2014; Thonnard et al., 2013; van Lommel, 2011). Although there is not yet a consensus on the definition of NDEs, those experiences have been described as "profound psychological events with transcendental and mystical elements typically occurring to individuals close to death or in situations of intense physical or emotional danger" (Greyson, 2000a). As a result of this intense experience, near-death experiencers (NDErs) usually report very detailed memories (Thonnard et al., 2013) that seem to be unchanged over time (Greyson, 2007). From a cognitive perspective, to date no theory can explain the rich phenomenology associated with NDE memories (Palmieri et al., 2014; Thonnard et al., 2013; van Lommel, 2011). Thus, one interesting issue is why such a clear memory trace is created for this experience and little is known about what exactly accounts for the enhanced memory.

For some years now, more and more NDErs' testimonies have been compiled which demonstrate the compelling intensity of this experience (Moody, 1975; Ring, 1980). While reported narratives appear to contain similarities and recurrent components (i.e. elements frequently reported by NDErs; e.g. feeling of peacefulness, out-of-body experiences (OBEs); Blanke \& Dieguez, 2009; Charland-Verville et al., 2014; Facco \& Agrillo, 2012), differences in terms of experience intensity (i.e. the depth of the experience) are reported (Charland-Verville et al., 2014). Notably, it seems that the intensity of NDE components differs when comparing NDErs

\footnotetext{
* Corresponding authors.

E-mail addresses: cmartial@ulg.ac.be (C. Martial), coma@chu.ulg.ac.be (S. Laureys).
} 
recruited in retrospective versus prospective studies -all features seem more frequently reported in retrospective as compared to prospective studies (Charland-Verville et al., 2014; Mobbs \& Watt, 2011). Finally, in some cases, NDEs are so intense that the NDErs will considerably change their personal attitudes, beliefs, and set of values (e.g. a decreased fear of death, an increase in spirituality, a greater appreciation of life) in a sustainable manner (Bauer, 1985; van Lommel, van Wees, Meyers, \& Elfferich, 2001).

Because the scientific literature devoted to the investigation of NDE memories is limited, one may attempt to better understand their particularities using the broader literature on autobiographical memory. If we consider autobiographic memory as "memory for the events of one's life" (Conway \& Rubin, 1993; see the Self-Memory System (SMS); Conway \& Pleydell-Pearce, 2000; Conway, Singer, \& Tagini, 2004), we could consider NDE memories as part of this memory system. The literature has shown that intensity of an experience affects the properties of the subsequent autobiographical memories more so than do valence or the age of the memory (e.g. Holmes, 1970; Talarico, LaBar, \& Rubin, 2004). Highly intense events are firmly anchored and remembered in memory (Bradley, 1994) and this is partly due to associated emotions. In the literature certain models suggest that the effects of emotion on memory could be explained without suggesting specific mechanisms associated with the emotional arousal (e.g. Bradley, 1994). From that perspective, the enhanced memory observed for emotional events might be due to "ordinary" factors (e.g. enhanced attention and/or increased elaboration) -as is the case with non-emotional events. In contrast, other models do suggest the existence of some additional special mechanisms associated with emotional arousal (e.g. McGaugh, 2000). Neural and hormonal mechanisms specific to emotional stimuli might influence their memory encoding (e.g. notably because of release of hormones; Cahill \& McGaugh, 1998; McGaugh, 2000), leading to more elaborated memory representations (Bradley, 1994). Since NDEs are known to imply a great emotional involvement (generally positive in valence) and to be high intensity (Moody, 1975), we can easily suggest that NDE memories can then benefit from a special encoding and storage (e.g. strong consolidation) that make them more phenomenologically detailed and more persistent than other kinds of memories. From the experiencers' perspective, NDE memories are characterized by a sense of "phenomenological certainty" (Dell'Olio, 2010). Recently, Thonnard et al. (2013) investigated NDE memories using the Memory Characteristics Questionnaire (MCQ; Johnson, Foley, Suengas, \& Raye, 1988) built to analyze phenomenological characteristics of real and imagined memories, and showed that NDE memories -as defined by the Greyson NDE scale (i.e. total score $\geq 7 / 32$; Greyson, 1983)- contain more phenomenological characteristics (e.g. emotions, contextual and sensory information) than imagined, real event and coma memories. This study suggests that NDEs cannot be considered as imagined event memories but rather a sort of "hyper reality" and seem unrivalled memories. Moreover, Greyson (2007) has shown that reports of NDEs have not changed over time, in assessing reported second accounts 20 years after the original one. Therefore, NDE memories seem to have very rich phenomenological characteristics and are stable over time. From a neurological perspective, NDE memories have been investigated in only very few studies. Nonetheless, Palmieri et al. (2014) have replicated Thonnard et al.' (2013)' findings and have further shown using electroencephalography (EEG) recordings that, at a neural level, NDE memories are stored as "episodic memories of events experienced in a peculiar state of consciousness" -and not as imagined event memories. More generally, the crucial question remains as to where and how the brain can store this experience (Agrillo, 2011).

Surely, other influencing factors can intervene in the creation of an exceptionally clear memory trace. As the term itself suggests, NDEs typically occur in situations in which people are close to death or are perceived as such. This context might strengthen the intensity of what they perceived and also makes the event "threatening" for individuals, independently of the associated positive feelings. Through evolution, human memory has developed the ability to preferentially retain events that are relevant for survival. Indeed, it would be adaptive to integrate relevant information on adverse events to be prepared for them in the future (see Porter \& Peace, 2007). However, regarding the memory characterization, it seems that it is the perception of the experience that is relevant, and not being "near-death" as coma memories include less phenomenological characteristics than NDE memories (Thonnard et al., 2013). Furthermore, NDEs seem to be (at least in part) due to physiological mechanisms, because NDErs really perceived the experience while we do not have any certainty that there are associated and appropriate stimulus existing in reality (Braithwaite, 2008). Indeed, it seems that NDEs have physiological origins -for example, OBEs caused by an impairment of temporo-parietal area structure (Blanke \& Arzy, 2005; Blanke, Landis, Spinelli, \& Seeck, 2004). Finally, to face with those potentially dangerous situations, humans can develop various adaptive mental and physical responses, including dissociation. Psychological theories have proposed that NDEs are dissociative states in which individuals experience a dissociation of the self-identity from bodily sensations (Irwin, 1993), leading them to experience pleasurable dimensions and sensations instead of the unpleasant event itself (Pfister, 1930). As a support to this view, Greyson (2000b) suggested that NDEs are probably more compatible with a normal response to stress than a pathological disorder. We can then consider NDEs as an integral part of an adaptive response to physical or emotional danger.

In psychological science, subjective self-report scales and questionnaires have been developed to collect data on many subjective states and contents of consciousness. However, while a growing number of such scales have been published on several different topics, there are only a very limited number of scales developed to collect data about NDEs specifically. To date, the most widely used standardized tool to identify NDEs in research is the Greyson NDE scale (Greyson, 1983). This scale provides a cut-off score (i.e. total score $\geq 7 / 32$; Greyson, 1983) permitting a standardized identification of NDErs. The Greyson NDE scale reflects the intensity of the NDE since it considers the amount of ticked experienced dimensions (i.e. $0=$ "not present" or presence of the item) and the gradation of intensity in provided scoring (i.e. 1 = "mildly or ambiguously present," and 2 = "definitively present"). Therefore, according to the scale, the Greyson NDE scale total score (out of total possible 32 points) reflects the NDE overall intensity (Greyson, 1983; Lange, Greyson, \& Houran, 2004). Few other authors have undertaken the considerable challenge of designing scales to assess NDEs and only two other scales have been proposed: The Weighted Core Experience Index (WCEI; Ring, 1980) and a short version of the 16-item Greyson NDE scale (Greyson, 1983) called The Near-Death Experience Scale-6 scale (NDE-6; Prosnick \& Evans, 2003). However, Ring's WCEI was neither based on statistical analyses nor tested for coherence or reliability. Although Greyson's construction of the Greyson NDE scale has subsequently addressed these limitations, it seems that, in general, we remain rather limited to investigate this 
experience and its associated rich phenomenology. Nonetheless, other scales, but non-specific to NDEs, may be used to assess this experience and, in particular, its subsequent memory. Notably, some authors have used the MCQ (e.g. Palmieri et al., 2014; Thonnard et al., 2013) with the aim of assessing subjective qualities of NDEs' memory characteristics. In fact, the MCQ has been constructed, by design, in a more extensive area aiming at assessing all types of memory -whatever the event or content of the evaluated memory. More specifically, the MCQ permits to examine qualitative characteristics of memories, in terms of sensory and contextual details and cognitive processes involved in the recall of a memory. Nowadays, the Greyson NDE scale (Greyson, 1983) and the MCQ (Johnson et al., 1988) are the two most commonly used standardized questionnaires in research to evaluate the NDE and its memory.

Although described as occurring in near-death states where the brain is thought to be working with altered capacities, NDErs can generally give a very detailed narrative account of their experience (Moody, 1975; Thonnard et al., 2013) and it seems that the NDEs can differ in term of experience intensity (Charland-Verville et al., 2014). We then wondered about the variation of NDE memory details according to the intensity of the experience. To the best of our knowledge, no study has formally compared the association of the NDE intensity according to the Greyson NDE scale (Greyson, 1983) with the phenomenological characterization of this type of memory according to the MCQ (Johnson et al., 1988) in the same sample of individuals who have lived a NDE. From a theoretical perspective, although the subjective experience reported by NDErs does not itself provide an explanation, it nevertheless can give some indications as to which aspects of the NDE an explanation should account for. Using the Greyson NDE scale (Greyson, 1983) and the MCQ (Johnson et al., 1988), the present study aimed at exploring (1) the association of both the NDE's intensity (Greyson NDE scale total score) and the amount of NDE memory characteristics (MCQ total score) with demographic data (age at interview, age at NDE and time since NDE); (2) the association of NDE's intensity (Greyson NDE scale total score) with the amount of NDE memory characteristics (MCQ total score) and, more in particular, (3) with the different phenomenological characteristics of NDE memory (MCQ items).

\section{Material and methods}

Participants were recruited via the International Associations for Near-Death Studies (IANDS France and IANDS Flanders) and the Coma Science Group (University and University Hospital of Liège, Belgium). Participants were mailed a questionnaire including the Greyson NDE scale (Greyson, 1983), the Memory Characteristics Questionnaire (MCQ; Johnson et al., 1988), and items about sociodemographic (gender, age at NDE, age at interview) and clinical (time since NDE, presence of life-threatening event, etiology of coma, presence of coma - i.e. a period of unconsciousness $>1 \mathrm{~h}$; Posner, Saper, \& Plum, 2007). We first assessed the NDE memory using the Greyson NDE scale. This scale is a validated (Greyson, 1983; Lange et al., 2004) 16-item multiple-choice tool used to permit a standardized identification of NDEs with a total score cut-off of 7 and to quantify the intensity of the NDE (i.e. total score ranging

Table 1

The Greyson NDE Scale (Greyson, 1983).

\begin{tabular}{|c|c|c|}
\hline Feature & Question & Response \\
\hline Altered time perception & "Did time seem to speed up or slow down?" & $\begin{array}{l}0=\text { No; } 1=\text { Time seemed to go faster or slower than usual; } 2=\text { Everything } \\
\text { seemed to be happening at once, or time stopped or last all meaning }\end{array}$ \\
\hline Speeded thoughts & "Were your thoughts speeded up?" & $0=$ No $; 1=$ Faster than usual; $2=$ Incredibly fast \\
\hline Life review & "Did scenes from your past come back to you?" & $\begin{array}{l}0=\text { No; } 1=\text { Remembered many past events; } 2=\text { Past flashed before me, out } \\
\text { my control }\end{array}$ \\
\hline Understanding & $\begin{array}{l}\text { "Did you suddenly seem to understand } \\
\text { everything?" }\end{array}$ & $0=$ No $; 1=$ About myself or others; $2=$ About the universe \\
\hline Peacefulness & "Did you have a feeling of peace or pleasantness?" & $0=$ No $; 1=$ Relief or calmness; $2=$ Incredible peace or pleasantness \\
\hline Happiness/joy & "Did you have a feeling of joy?" & $0=$ No $; 1=$ Happiness; $2=$ Incredible joy \\
\hline Harmony/unity & $\begin{array}{l}\text { "Did you feel a sense of harmony or unity with the } \\
\text { universe?" }\end{array}$ & $0=$ No; $1=$ No longer in conflict with nature; $2=$ United, one with the world \\
\hline Bright light & $\begin{array}{l}\text { "Did you see, or feel surrounded by, a brilliant } \\
\text { light?" }\end{array}$ & $\begin{array}{l}0=\text { No; } 1=\text { Unusually bright light; } 2=\text { Light clearly of mystical or other- } \\
\text { worldly origin }\end{array}$ \\
\hline Heightened senses & "Were your senses more vivid than usual?" & $0=$ No $; 1=$ More vivid than usual; $2=$ Incredibly more vivid \\
\hline Extrasensory perception & $\begin{array}{l}\text { "Did you seem to be aware of things going on } \\
\text { elsewhere, as if by extrasensory perception (ESP)?" }\end{array}$ & $\begin{array}{l}0=\text { No; } 1=\text { Yes, but the facts not yet corroborated; } 2=\text { Yes, and the facts } \\
\text { later corroborated }\end{array}$ \\
\hline Precognitive visions & "Did scenes from the future come to you?" & $\begin{array}{l}0=\text { No; } 1=\text { Scenes from my personal future; } 2=\text { Scenes from the world's } \\
\text { future }\end{array}$ \\
\hline Out-of-Body Experience & "Did you feel separated from your body?" & $\begin{array}{l}0=\mathrm{No} ; 1=\text { Lost awareness of my body; } 2=\text { Clearly left my body and existed } \\
\text { outside it }\end{array}$ \\
\hline Unearthly environment & $\begin{array}{l}\text { "Did you seem to enter some other, unearthly } \\
\text { world?" }\end{array}$ & $\begin{array}{l}0=\text { No; } 1=\text { Unfamiliar and strange place; } 2=\text { Clearly mystical or unearthly } \\
\text { realm }\end{array}$ \\
\hline Mystical being/presence & $\begin{array}{l}\text { "Did you seem to encounter a mystical being or } \\
\text { presence, or hear an unidentifiable voice?" }\end{array}$ & $\begin{array}{l}0=\text { No; } 1=\text { Unidentifiable voice; } 2=\text { Definite being, or voice clearly of } \\
\text { mystical or unearthly origin }\end{array}$ \\
\hline $\begin{array}{l}\text { Encounter with deceased/ } \\
\text { religious spirits }\end{array}$ & "Did you see deceased or religious spirits?" & $0=$ No; $1=$ Sensed their presence; $2=$ Saw them \\
\hline Border/point of no return & "Did you come to a border or point of no return?" & $\begin{array}{l}0=\mathrm{No} ; 1=\mathrm{A} \text { conscious decision to "return" to life; } 2=\text { A barrier I was not } \\
\text { permitted to cross; or "sent back" to life involuntarily }\end{array}$ \\
\hline
\end{tabular}


Table 2

Memory Characteristics Questionnaire (MCQ; Johnson et al., 1988; adapted from D'Argembeau and Van der Linden, 2008).

\begin{tabular}{|c|c|c|}
\hline Characteristic & Question & Response \\
\hline Feeling of re-experiencing & "While remembering the event, I feel as though I am mentally reliving it" & $1=$ not at all, 7 completely \\
\hline Visual details & "My memory for this event involves visual details" & $1=$ none, $7=$ a lot \\
\hline Other sensory details & $\begin{array}{l}\text { "My memory for this event involves other sensory details (sounds, smells, } \\
\text { and/or tastes)" }\end{array}$ & $1=$ none, $7=$ a lot \\
\hline Location & "I remember the location where the event took place" & $1=$ not at all clear, $7=$ very clearly \\
\hline Time & "I remember the time of the day where the event took place" & $1=$ not at all clear, $7=$ very clearly \\
\hline Coherence & $\begin{array}{l}\text { "While remembering the event, it comes to me as a coherent story and not } \\
\text { as an isolated scene" }\end{array}$ & $1=$ not at all, $7=$ completely \\
\hline Verbal component & "While remembering the event, it comes to me in words" & $1=$ not at all, $7=$ a lot \\
\hline Feeling emotions & $\begin{array}{l}\text { "While remembering the event, I feel the emotions I felt when the event } \\
\text { occurred" }\end{array}$ & $1=$ not at all, $7=$ completely \\
\hline Real/imagine & $\begin{array}{l}\text { "I believe the event in my memory really occurred in the way I remember } \\
\text { it and that I have not imagined or fabricated anything that did not occur" }\end{array}$ & $1=100 \%$ imaginary, $7=100 \%$ real \\
\hline One's own actions & "I remember what I did during this event" & $1=$ not at all, $7=$ very clearly \\
\hline One's own words & "I remember what I said during this event" & $1=$ not at all, $7=$ very clearly \\
\hline One's own thoughts & "I remember what I thought during this event" & $1=$ not at all, $7=$ very clearly \\
\hline Visual perspective & $\begin{array}{l}\text { "Previous studies have shown that people can report that they can } \\
\text { visualize different memories from different points of view. Using the } \\
\text { bellow mentioned categories, from which point of view do you see } \\
\text { yourself? (A) In your memory, you imagine the scene as an observer could } \\
\text { see it. As an observer, you can see yourself and other aspects of the } \\
\text { situation. (B) In your memory, you imagined the scene from your own } \\
\text { point of view (through you own eyes). You are an actor. (C) Any of the } \\
\text { above-mentioned perspectives described the way you remember the } \\
\text { situation. At which point are you observer or actor in the situation" }\end{array}$ & $1=$ totally observer; $7=$ totally actor \\
\hline Valence & "When the event happened, my emotions were" & $\begin{array}{l}-3=\text { very negative, } 0=\text { neutral } \\
+3=\text { very positive }\end{array}$ \\
\hline Personal importance & $\begin{array}{l}\text { "This event is important to me (it involves an important theme or episode } \\
\text { in my life)" }\end{array}$ & $\begin{array}{l}1=\text { not at all important, } 7=\text { very } \\
\text { important }\end{array}$ \\
\hline Reactivation frequency & "Since it occurred, I have thought or talked about this event" & $1=$ not at all, $7=$ very often \\
\hline
\end{tabular}

from 0 to 32). The Greyson NDE scale assesses core content components of 16 NDE features (Table 1). For each item, the scores are arranged on an ordinal scale ranging from 0 to 2 (i.e. $0=$ "not present," 1 = "mildly or ambiguously present," and $2=$ "definitively present"). Participants whose experience did not meet the standardized criteria (i.e. Greyson NDE scale total score < 7/32; Greyson, 1983) were not included in the present study. We also assessed the participants' memories characteristics using a modified version (see Table 2; D'Argembeau \& Van der Linden, 2008) of the MCQ (Johnson et al., 1988). This version encompasses 16 rating scales assessing feeling of re-experiencing, visual details, other sensory details, location, time, coherence, verbal component, emotion while remembering, belief that the event is real, one's own actions, words and thoughts, visual perspective, emotional valence, personal importance, and reactivation frequency. A MCQ total score was derived summing all the 16 items (each on a 1-7 points Likert scale) and referred to as the amount of memory characteristics (i.e. higher total scores reflect greater amount of memory characteristics). No incentive was offered for participation. Completion of the anonymous questionnaire was voluntary and taken as consent for participation in the survey. The study was approved by the ethics committee of the Faculty of Medicine of the University of Liège.

Pearson's correlation tests were used to measure the linear association between variables. More specifically, correlations were obtained using both the Greyson NDE scale total score and the MCQ total score with each demographic variable (age at interview, age at NDE and time since NDE). Then, correlation was done between the Greyson NDE scale total score and the MCQ total score. Finally, correlations were obtained using the Greyson NDE scale total score and each of the 16 MCQ items. We used the Shapiro-Wilk test to evaluate the hypothesis that a given sample was from a normal population. To avoid type I errors, the level of significance undergoes a Bonferroni adjustment $(\mathrm{p}<0.0021)$ in all statistical analyses.

\section{Results}

\subsection{Demographic data}

The distributions of demographic data and scores follow a normal distribution. The study sample included 152 individuals who have had a NDE described experience (i.e. meeting the criteria for NDE: Greyson NDE scale total score $\geq 7 / 32$; Greyson, 1983) after a life-threatening event (i.e. a severe brain insult; e.g. cardiac arrest, traumatism). Table 3 shows the demographic characteristics of the entire study cohort. 
Table 3

Participants' descriptive and demographic data $(\mathrm{N}=152)$. The NDE intensity (Greyson NDE scale total score) and the amount of memory characteristics (MCQ total score)

\begin{tabular}{lc}
\hline & Total \\
& $\mathrm{N}=152$ \\
\hline Demographics & $82(54 \%)$ \\
Gender-female & $56 \pm 10$ \\
Age at interview (Mean in years \pm SEM) & $33 \pm 14$ \\
Age at NDE (Mean in years \pm SEM) & $23 \pm 14$ \\
Time since NDE (Mean in years \pm SEM) & \\
Scales & $16 \pm 5$ \\
Greyson NDE scale total score (Mean \pm SEM, range) & $7-30$ \\
MCQ total score (Mean \pm SEM, range) & $86 \pm 11$ \\
& $41-110$ \\
\hline
\end{tabular}

$\mathrm{SEM}=$ Standard Error of the Mean.

\subsection{Correlations between both scale total scores and demographic data}

There were no significant associations with the time since NDE and total scores on the Greyson NDE scale and the MCQ, meaning that the intensity of NDE and the amount of NDE memory characteristics do not appear to vary with the amount of time that had elapsed since NDE. There were also no significant correlations between variables age at interview and at NDE and the Greyson NDE and MCQ total scores (see Table 4).

\subsection{Correlations between Greyson NDE scale total score, MCQ total score and items}

Greyson NDE scale total score was positively correlated with MCQ total score $(r=0.29, \mathrm{p}<0.0005)$, suggesting that individuals who described more intense NDEs also reported more phenomenological characteristics of NDEs (see Table 4). Analyses with MCQ items showed positive correlations between the Greyson NDE scale total score and 3 of those items: other sensory details ( $r=0.29$, $\mathrm{p}<0.0005$; MCQ item 3), personal importance $(\mathrm{r}=0.22, \mathrm{p}<0.002$; MCQ item 15), and reactivation frequency $(\mathrm{r}=0.28$, $\mathrm{p}<0.0005$; MCQ item 16). This suggests that individuals who described more elaborate NDEs also reported more sensory characteristics (i.e. sounds, smells and tastes), personal importance and reactivation frequency. No further significant correlations were found between the Greyson NDE scale total score and the other MCQ items (see Table 4).

Table 4

Correlations between demographic data, Greyson NDE scale total score, MCQ total score and MCQ items.

\begin{tabular}{|c|c|c|}
\hline \multicolumn{3}{|l|}{ Demography } \\
\hline Age at NDE & $-0.14(0.079)$ & $0.01(0.894)$ \\
\hline Time since NDE & $0.06(0.435)$ & $0.005(0.951)$ \\
\hline \multicolumn{3}{|l|}{ MCQ total score \& items } \\
\hline MCQ total score & $0.29(0.0003)$ & - \\
\hline $\begin{array}{l}\text { Feeling of re- } \\
\text { experiencing }\end{array}$ & $0.10(0.233)$ & - \\
\hline Visual details & $0.07(0.396)$ & - \\
\hline Other sensory details & $0.29(0.0002)$ & - \\
\hline Location & $-0.09(0.249)$ & - \\
\hline Time & $0.05(0.538)$ & - \\
\hline Coherence & $0.17(0.04)$ & - \\
\hline Verbal component & $0.13(0.122)$ & - \\
\hline Feeling emotions & $0.18(0.026)$ & - \\
\hline Real/imagine & $0.20(0.014)$ & - \\
\hline One's own actions & $-0.04(0.581)$ & - \\
\hline One's own words & $0.14(0.086)$ & - \\
\hline One's own thoughts & $0.04(0.644)$ & - \\
\hline Visual perspective & $0.10(0.236)$ & - \\
\hline Valence & $0.16(0.05)$ & - \\
\hline Personal importance & $0.22(0.002)$ & - \\
\hline Reactivation frequency & $0.28(0.0004)$ & - \\
\hline
\end{tabular}

Data are Pearson's correlations (p). Results in bold are statistically significant (at $p<0.0021$ after Bonferroni correction). 


\section{Discussion}

This retrospective study shows that the intensity of the NDE (i.e. the Greyson NDE scale total score) appears to be positively correlated with the overall amount of retrospective phenomenological characteristics identified with the MCQ (i.e. the MCQ total score). In other words, participants who scored higher on the Greyson NDE scale also scored higher on the MCQ. This suggests that the more intense the NDE is, the more the memory seems to be phenomenologically detailed when NDErs later recall it. It can then be hypothesized that the deeper the NDE is, the more the memory seems to be anchored and to benefit from a special encoding, leading the memory to contain a greater amount of phenomenological characteristics. Moreover, one can argue that NDE memory characteristics would vary with the amount of time that had elapsed since the experience. However, it does not seem to be the case since we do not find a link between the amount of time that had elapsed since NDE and the amount of memory characteristics. Furthermore, we also find no association between the NDE's intensity and the amount of time that had elapsed since the NDE. Despite our study is not a test-retest design, our data support the view that the intensity of NDE does not seem to increase or decrease with the time that had elapsed since the experience. In fact, except Greyson's (2007) study, it seems that very little is known about the long-term retention of NDE memories.

Since NDEs are complex subjective experiences typically including various features, our study also clarifies that the NDE's intensity is associated in particular with MCQ items of sensory details (concerning sounds and smells), personal importance and reactivation frequency. Interestingly, we find that the presence of sensory details in NDErs' memory varies with experience's intensity. Since some studies have suggested that emotional valence increases the amount of sensory details in memory (e.g. Schaefer \& Philippot, 2005), it seems reasonable to suggest that the NDE -as highly emotional event (Thonnard et al., 2013)- may be encoded and stored by a special memory mechanism that typically operates during the encoding of emotionally arousing events. For example, we can speculate that intensity could increase attentional mechanisms and then be beneficial for all reported sensory details.

We also observe a relationship between the NDE's intensity and the reactivation frequency item on the MCQ. That is, the more intense the NDE is, the more frequently the NDE seems to be reactivated in memory. Intense events are more likely to be rehearsed which in turn can enhance the amount of phenomenological characteristics in memory (Berntsen, 1996; Berntsen, 1998). Recently, Thonnard et al. (2013) showed that NDE memories were as likely to be reactivated in memory as other real and imagined events memories or coma memories that did not classify as a NDE based on the Greyson NDE scale (i.e. total score of Greyson < 7/32; Greyson, 1983). In the present study, we nevertheless note the association between intensity and reactivation frequency variables. On the one hand, experience memories may be intentionally and/or voluntarily brought into awareness and, on the other hand, experience memories may be reactivated internally and/or externally -sharing it with other people for example. Our results are consistent with previous ones showing that high-intensity events memories tend to be more frequently thought or talked about than low-intensity events memories (Berntsen, 1996; Berntsen, 1998; Waters \& Leeper, 1936).

Finally, we find that NDE's intensity varies with the personal importance NDErs attached to the experience, suggesting that the more intense the NDE is, the more the NDE could be considered as an important episode in NDEr's life. Personal importance given to the NDE could possibly enhance the overall perceived phenomenological characteristics of NDE memories. According to Conway's Self-Memory System (SMS; Conway \& Pleydell-Pearce, 2000; Conway et al., 2004) model, autobiographical memories are "the transitory mental constructions of a complex goal-driven set of control processes collectively referred to as the working self" (Conway et al., 2004). Only a relatively small part of autobiographical memories may remain accessible in long-term memory and this selection should depend on their given relevance to longer-term goals and consequently to the future. This system consists of two main strongly interconnected components: the working self and the autobiographical memory knowledge base. In this theoretical framework, one could consider that the NDE was particularly well integrated by those both memory components -notably because the NDE has become a highly important self-defining experience- and this could explain the long-lasting accessibility of its memory (including their phenomenological characteristics). While NDEs are closely related to experiencers' own identity (Greyson, 2007; Moody, 1975) and because of its self-defining personal importance, NDE memories could be consider as a type of "self-defining memories" (personally meaningful and emotionally evocative memories; Singer, 2005).

We further hypothesize that NDE memories share similar certain encoding conditions as "flashbulb memories", although both types of memories may differ in term of the reminded experience and context. A "flashbulb memory" can be defined as "a vivid, longlasting memory for the circumstances surrounding the reception of news about a surprising or shocking event" (Davidson \& Glisky, 2002). "Flashbulb memory" and NDE memory both are surprising events with an intense emotional content and they are perceived as very important life event for the experiencer, although sometimes perceived subsequently (Davidson \& Glisky, 2002). However, one may also note that NDEs may be even more intense when experienced because "flashbulb memories" refer to memories for the circumstances in which a piece of news was learned (i.e. where they were when the event occurred, what they were doing) while NDE memories refer to memories of a personally lived experience classically occurring during a life-threatening situation. Nevertheless, it appears that, in both cases, the event seems to benefit from a preferential encoding that makes then them more details than other real or imagined events memories (for NDE memories: see Thonnard et al., 2013; for "flashbulb memories": see Finkenauer et al., 1998; Rubin \& Kozin, 1984). Moreover, previous studies have shown that both personal importance and rehearsal frequency -variables identified in the present study as being associated with NDE's intensity- are two variables playing a crucial role in the maintenance of vivid memories, such as "flashbulb memories" (e.g. Bohannon \& Symons, 1992; Finkenauer et al., 1998; Wright \& Nunn, 2000). It even appears that these variables are the two most significant factors that allow the differentiation of flashbulb and non-flashbulb memories (Tekcan \& Peynircioğlu, 2002) -even more significant than other variables such as emotional valence or the surprise effect. In short, these three variables assessed in the present study -i.e. sensory details, personal importance and reactivation frequency- 
appear to vary with intensity of the NDE and might overlap in explaining these intense NDE memories and its associated rich phenomenology.

Still using MCQ items, intensity variations in reported NDEs do not seem to be associated with the other memory characteristics (emotional information, visual details, confidence, visual perspective, feeling of re-experiencing) assessed by the MCQ. Intriguingly, emotional information (i.e. emotional valence, emotion while remembering) does not also appear to vary the NDE's intensity. While NDEs appear to include extremely high emotional content -containing even more emotional characteristics than real events memories (Thonnard et al., 2013), we find that the presence of emotional details in NDErs' memory may fluctuate independently of intensity variation experienced by NDErs.

From a broader cognitive perspective, the enhanced memory observed for NDEs is interesting as it suggests that humans might be able to recall (or elaborate later) memories of a moment characterized by an atypical state of consciousness (i.e. altered state of consciousness; Moody, 1975). Nevertheless, it is still unclear when exactly these events are experienced as well as when their memory encoding precisely occurs. Although many authors have now improved consistency in the field of NDEs, none of the neuropsychological and cognitive models of memory appears to fully explain the encoding and storage of NDEs. These experiences are described as occurring in near-death states where the brain and its associated processes are thought to be working with altered capacities, however, those ones seem to be firmly anchored and remembered in NDErs' memories.

While resuscitation techniques are improving and providing more reported NDE testimonies (van Lommel et al., 2001), only very few scales are present to investigate the phenomenon. In this study, the correlation between both total scores also indicates a relationship between variables represented by the two main questionnaires used to assess a NDE and its memory in the same sample of individuals who have lived a NDE. We observe that individuals who scored higher on one of the questionnaires also scored higher on the other one. Then, one can ask to what extent there is an overlap between the items of the two questionnaires and to what extent they evaluate the same aspects of the experience. However, although the correlation is highly significant, we find a relatively weak linear relation. Instead, this suggests that both questionnaires may be testing different and complementary aspects of the experience. The Greyson NDE scale focuses on the content of the NDE and its intensity (only) at a phenomenological level while the MCQ assesses qualitative characteristics of NDE memories and cognitive processes involved in its recall. Although the Greyson NDE scale inevitably assesses the NDE memory by retrospectively questioning the individual about what he is remembering, the MCQ differs from the Greyson NDE scale by exploring the multimodal aspect (i.e. separately measuring sensory, perceptual, semantic and spatio-temporal components) of the memory. This may permit to observe distinct implications of those aspects specific to NDEs in the investigation of its rich phenomenology. Finally, the MCQ also allows assessing negative emotions and confidence in the memory -which is currently not possible with the Greyson NDE scale.

At present, no study has formally compared the association of the NDE's intensity and the phenomenological characterization of NDE memory. This work then opens the way to new perspectives by observing the association of memory characteristics with NDE's intensity in the same sample of NDErs. We think that a more complete phenomenological assessment of NDEs is important for a better description and ultimately a better understanding of the underlying psychological and cognitive mechanisms. Nevertheless, although we find a positive correlation between the intensity of NDE and its amount of associated memory characteristics, the question of cause and effect remains to be addressed in further work. In particular, the present results do not allow us to say whether it is the increasing intensity of NDE that leads to a greater amount of memory characteristics or the inverse pattern. In addition, another variable could also explain the associated variations we find in this study. For example, it may be possible that the way in which individuals encode and recall information is one variable influencing how they respond to both questionnaires. In addition, it is important to highlight another limitation of the present study: this investigation may be subject to selection bias and hence may not be representative of NDErs in general. Indeed, NDErs who do not contact us intentionally may possibly experience NDE memory differently from those who do. Nevertheless, our study embraces a large sample and, in our view, those results are important as people might know more about it and feel more comfortable.

\section{Conclusions}

The amount of memory details in a NDE (i.e. the MCQ total score) appears to be positively associated with the intensity of the lived experience (i.e. the Greyson NDE scale total score). More specifically, our results highlight that sensory details (i.e. sounds, smells and tastes), personal importance and reactivation frequency seem to vary with the intensity of the NDE (i.e. the Greyson NDE scale total score). The challenge lies in explaining how memory formation can occur under life-threatening conditions in which the individual is thought to be unconscious and at a time when memory formation would not be expected to operate effectively. Understanding the particular mechanisms of NDE memories and their formation will improve our understanding of the NDE phenomenon and, more generally, in our understanding of consciousness and its relation to brain.

\section{Competing interests}

None.

\section{Acknowledgements}

The authors would like to thank our subjects for contributing their time to participate in this study and the International Associations for Near-Death Studies (IANDS France and IANDS Flanders) and particularly J.-P. Jourdan who helped with near-death 
experiencers recruitment. The authors thank Dr. A. D'Argembeau for reviewing the manuscript and providing his insightful comments. This work was supported by the Belgian National Funds for Scientific Research (FNRS), the French Speaking Community Concerted Research Action (ARC - 06/11 - 340), NSERC discovery grant, IAP research network P7/06 of the Belgian Government (Belgian Science Policy), the BIAL Foundation, the European Commission, the James McDonnell Foundation, Mind Science Foundation, the European space agency (ESA), the Public Utility Foundation 'Université Européenne du Travail' and "Fondazione Europea di Ricerca Biomedical".

\section{References}

Agrillo, C. (2011). Near-death experience: Out-of-body and out-of-brain? Review of General Psychology, 15(1), 1-10.

Bauer, M. (1985). Near-death experiences and attitude change. Anabiosis: The Journal of Near-Death Studies, 5, 39-47.

Berntsen, D. (1996). Involuntary autobiographical memories. Applied Cognitive Psychology, 10, 435-454.

Berntsen, D. (1998). Voluntary and involuntary access to autobiographical memory. Memory, 6, 113-141.

Blanke, O., \& Arzy, S. (2005). The out-of-body experience: Disturbed self-processing at the temporo-parietal junction. Neuroscientist, 11, 16-24.

Blanke, O., \& Dieguez, S. (2009). Leaving body and life behind: Out-of-body and near-death experience. In S. Laureys, \& G. Tononi (Eds.), The neurology of consciousness (pp. 303-325). London: Academic Press.

Blanke, O., Landis, T., Spinelli, L., \& Seeck, M. (2004). Out-of-body experience and autoscopy of neurological origin. Brain, 127, 243-258.

Bohannon, J. N., \& Symons, V. L. (1992). Flashbulb memories: Confidence, consistency, and quantity. New York: Cambridge University Press.

Bradley, M. (1994). Emotional memory: A dimensional analysis. In S. Van Goozen, N. E. Van de Poll, \& J. A. Sergeant (Eds.), The emotions: Essays on emotion theory (pp. 97-134). Hillsdale, NJ: Erlbaum.

Braithwaite, J. J. (2008). Towards a cognitive neuroscience of the dying brain. Skeptic, 21, 8-16.

Cahill, L., \& McGaugh, J. L. (1998). Mechanisms of emotional arousal and lasting declarative memory. Trends in Neurosciences, 21, 294-299.

Charland-Verville, V., Jourdan, J.-P., Thonnard, M., Ledoux, D., Donneau, A.-F., Quertemont, E., \& Laureys, S. (2014). Near-death experiences in non-life-threatening events and coma of different etiologies. Frontiers in Human Neuroscience, 8, 203.

Conway, M., \& Pleydell-Pearce, C. W. (2000). The construction of autobiographical memories in the self-memory system. Psychological Review, 107, 261-288.

Conway, M. A., \& Rubin, D. C. (1993). The structure of autobiographical memory. In A. E. Collins, S. E. Gathercole, M. A. Conway, \& P. E. Morris (Eds.), Theories of memory (pp. 103-137). Hove, Sussex: Erlbaum.

Conway, M. A., Singer, J. A., \& Tagini, A. (2004). The self and autobiographical memory: Correspondence and coherence. Social Cognition, 22(5), 491-529.

D'Argembeau, A., \& Van der Linden, M. (2008). Remembering pride and shame: Self-enhancement and the phenomenology of autobiographical memory. Memory, 16, $538-547$.

Davidson, P. S. R., \& Glisky, E. L. (2002). Is flashbulb memory a special instance of source memory? Evidence from older adults. Memory, 10 , 99-111.

Dell'Olio, A. J. (2010). Do near-death experiences provide a rational basis for belief in life after death? Sophia, 49, $113-128$.

Facco, E., \& Agrillo, C. (2012). Near-death-like experiences without life-threatening conditions or brain disorders: A hypothesis from a case report. Frontiers in Psychology, 3(490), 1-5.

Finkenauer, C., Luminet, O., Gisle, L., El-Ahmadi, A., van der Linden, M., \& Philippot, P. (1998). Flashbulb memories and the underlying mechanisms of their formation: Toward an emotional-integrative model. Memory and Cognition, 26(3), 516-531.

Greyson, B. (1983). The near-death experience scale. Construction, reliability, and validity. The Journal of Nervous and Mental Disease, 171(6), 369-375.

Greyson, B. (2000). Dissociation in people who have near-death experiences: Out of their bodies or out of their minds? The Lancet, 355(9202), 460-463.

Greyson, B. (2007). Consistency of near-death experience accounts over two decades: Are reports embellished over time? Resuscitation, 73, 407-411.

Greyson, B. (2000a). Near-death experiences. In E. Cardefia, S. J. Lynn, \& S. Krippner (Eds.), Varieties of anomalous experience: Examining the scientific evidence. Washigton, DC: American Psychological Association.

Heim, A. (1891). Notizen uber den Tod durch Absturtz. Jahrbuch des Schweizer Alpenclub, 27, 327-337.

Holmes, D. S. (1970). Differential change in affective intensity and the forgetting of unpleasant personal experiences. Journal of Personality and Social Psychology, 15, $234-239$.

Irwin, H. J. (1993). The near-death experience as a dissociative phenomenon: An empirical assessment. Journal of Near-Death Studies, 12 , 95-103.

Johnson, M. K., Foley, M. A., Suengas, A. G., \& Raye, C. L. (1988). Phenomenal characteristics of memories for perceived and imagined autobiographical events. Journal of Experimental Psychology: General, 117, 371-376.

Lange, R., Greyson, B., \& Houran, J. (2004). A Rasch scaling validation of a "core" near-death experience. British Journal of Psychology, 95, 161-177.

McGaugh, J. L. (2000). Memory: a century of consolidation. Science, 287, 248-251.

Mobbs, D., \& Watt, C. (2011). There is nothing paranormal about near-death experiences: How neuroscience can explain seeing bright lights, meeting the dead, or being convinced you are one of them. Trends in Cognitive Sciences, 15, 447-449.

Moody, R. A. (1975). Life after life. New York: Bantam Books.

Palmieri, A., Calvo, V., Kleinbub, J. R., Meconi, F., Marangoni, M., Barilaro, P., ... Sessa, P. (2014). "Reality" of near-death-experience memories: Evidence from a psychodynamic and electrophysiological integrated study. Frontiers in Human Neuroscience, 8, 429.

Pfister, O. (1930). Shockdenken und shockphantasien bei höchster todesgefahr. Zeitschrift für Psychoanalyse, 16, 430-455.

Porter, S., \& Peace, K. A. (2007). The scars of memory: A prospective, longitudinal investigation of the consistency of traumatic and positive emotional memories in adulthood. Psychological Science, 18, 435-441.

Posner, J. B., Saper, C. B., \& Plum, F. (2007). Diagnosis of Stupor and Coma. New-York, NY: Oxford University Press.

Prosnick, K. P., \& Evans, W. J. (2003). Validity and reliability of the Near-Death Experience Scale-6 (NDE-6). Journal of Near-Death Studies, 22 , 133-143.

Ring, K. (1980). Life at death: A scientific investigation of the near-death experience. New-York, NY: Coward, McCann \& Geoghegan.

Rubin, D. C., \& Kozin, M. (1984). Vivid memories. Cognition, 16, 81-95.

Schaefer, A., \& Philippot, P. (2005). Selective effects of emotion on the phenomenal characteristics of autobiographical memories. Memory, 13, 148-160.

Singer, J. A. (2005). Memories that matter: How to use self-defining memories to understand and change your life. Oakland: New Harbinger Publications.

Talarico, J. M., LaBar, K. S., \& Rubin, D. C. (2004). Emotional intensity predicts autobiographical memory experience. Memory and Cognition, 32, 1118-1132.

Tekcan, A. I., \& Peynircioğlu, Z. F. (2002). Effects of age on flashbulb memories. Psychology and Aging, 17, 416-422.

Thonnard, M., Charland-Verville, V., Brédart, S., Dehon, H., Ledoux, D., Laureys, S., \& Vanhaudenhuyse, A. (2013). Characteristics of near-death experiences memories as compared to real and imagined events memories. PLOS ONE, 8(3), e57620.

van Lommel, P. (2011). Near-death experiences: The experience of the self as real and not as an illusion. Annals of the New York Academy of Science, 1234, 19-28.

van Lommel, P., van Wees, R., Meyers, V., \& Elfferich, I. (2001). Near-death experience in survivors of cardiac arrest: A prospective study in the Netherlands. The Lancet, 358, 2039-2045.

Waters, R. H., \& Leeper, R. (1936). The relation of affective tone to the retention of experiences of daily life. Journal of Experimental Psychology, 19, $203-215$.

Wright, D. B., \& Nunn, J. A. (2000). Similarities within event clusters in autobiographical memory. Applied Cognitive Psychology, 14, 479-489. 